\title{
Popliteal artery transection associated with a minimally displaced tibial plateau fracture: a case report and review of the literature
}

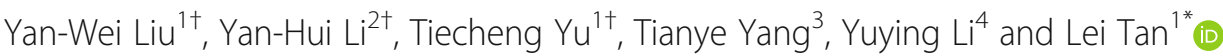

\begin{abstract}
Background: Poplital artery transection injury is potentially catastrophic, or even life-threatening. Severe traumas, including open fracture, gunshot, stabs, and knee dislocation and complex fracture of proximal tibia or distal femur, are the common causes of high rate of amputation due to popliteal artery trauma. No report mentions vascular injury associated with minimally displaced tibial plateau fracture in adult.

Case presentation: A 30-year-old male presented with popliteal artery transection injury associated with minimally displaced tibial plateau fracture. He presented to emergency department, $6 \mathrm{~h}$ after fall from ground into a 1 -m height hole. Physical examination suggested acute ischemia, with signs of paleness, coldness, anesthesia, hemorrhagic bullae below the right knee level. There was severe swelling and ecchymosis in popliteal fossa and around the leg with significant calf tenderness and pedal edema. Tibialis posterior, dorsalis pedis, and popliteal arterial pulses were not palpable. Radiograph suggested minimally displaced tibial plateau fracture with no evidence of knee dislocation. The patient was taken up for emergency surgery after consultation with vascular surgeon. During the closed reduction external fixation and compartment decompression, popliteal artery trunk was found transected and end-to-end repair was performed. During the post-operational period, no complication was developed and the patient was followed-up for 1 year. At the one-year follow-up, he acquired good stability of his right knee with full range of motion.
\end{abstract}

Conclusion: Significant swelling and ecchymosis should alert the surgeons to the possibility of vascular injury in knee joint injury, even if there is no fracture or dislocation, or fracture is minimally displaced.

Keywords: Popliteal artery transection, Minimally displaced, Tibial plateau fracture

\section{Background}

Poplital artery transection injury can have devastating consequences in patients, as irreversible ischemia can occur in as short as 6 to $8 \mathrm{~h}$. The most common cause of popliteal artery injuries is associated with open wounds-such as those from gunshot, stabs, open fractures or operations [1]. The second most common cause is the closed injuries associated with displaced fractures or dislocations, though some authors report injuries produced by blunt trauma [2]. Although popliteal artery

\footnotetext{
* Correspondence: tanlei1982@foxmail.com

†Yan-Wei Liu, Yan-Hui Li and Tiecheng Yu contributed equally to this work ${ }^{1}$ Department of Orthopedic Trauma, The First Hospital of Jilin University, Changchun, No. 71 Xinmin Street, Changchun, Jilin, China

Full list of author information is available at the end of the article
}

transection complicating a non-displaced proximal tibial epiphysis fracture has been reported [3], no report mentions vascular injury associated with tibial plateau fracture in the absence of displacement or dislocation in adult.

In this case report, we presented a single case of 30-year-old male with popliteal artery transection injury associated with minimally displaced tibial plateau fracture, was treated in time and saved the affected limb successfully.

\section{Case presentation}

A 30 -year-old male (body mass index, $28.8 \mathrm{~kg} / \mathrm{m} 2$ ) presented to our emergency department, $6 \mathrm{~h}$ after fall from ground into a 1-m height hole, with an isolated struck 


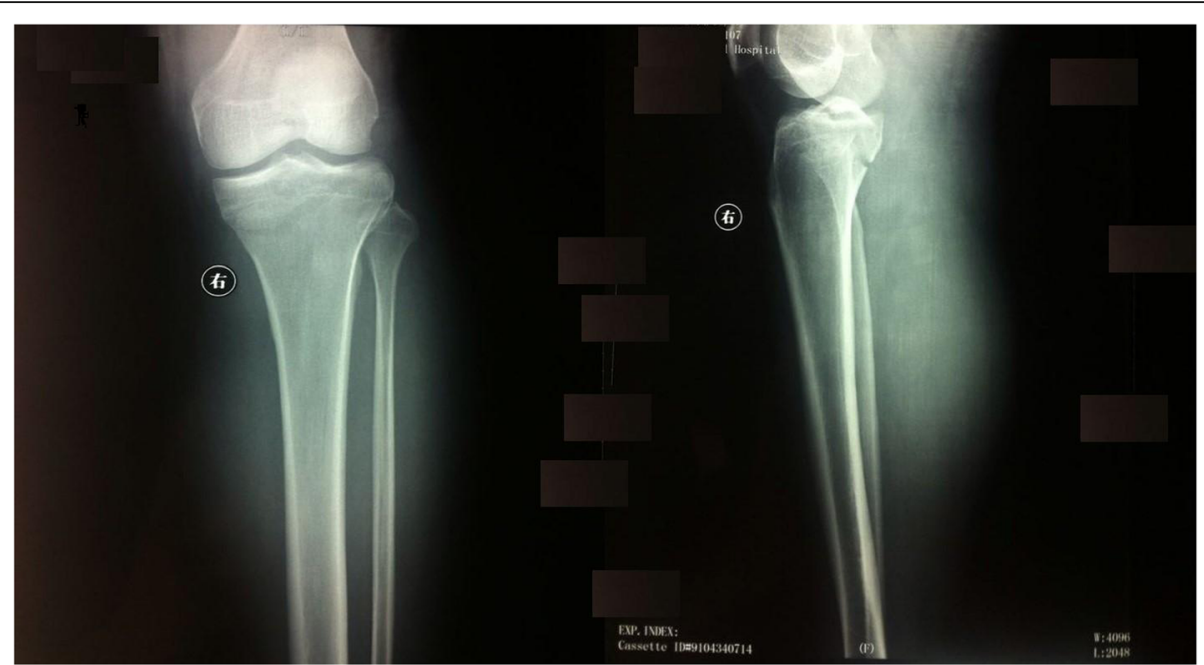

Fig. 1 An oblique fracture, involving the tibial spines, medial and lateral surfaces of the tibal plateau illustrated in an anteroposterior (left), and lateral radiographs (right)

injury of the right flexed knee while he was drunk. According to his parents' description, he walked for a short distance. He complained acute pain in his right knee when admitted.

In the immediate physical examination of the patient, the right knee level showed clear evidence of acute ischemia, with signs of paleness, coldness, anesthesia, hemorrhagic bullae. There was severe swelling and ecchymosis in popliteal fossa and around the leg, and there was significant calf tenderness and pedal edema. Tibialis posterior, dorsalis pedis, and popliteal arterial pulses were not felt, and capillary refill and pinprick bleeding were delayed. There was severe pain with passive stretch of the muscles when the toes or foot are plantar flexed.

Radiograph was taken which showed minimally displaced tibial plateau two columns fracture with no evidence of knee dislocation, but significant soft tissue swelling (Fig. 1). After consultation with vascular surgeon, we believed that there was a high probability of popliteal artery injury. The patient was sent to operation immediately.

Emergency surgery was performed to salvage the ischemic limb at $6.5 \mathrm{~h}$ after injury. The patient was placed in the supine position under general anesthesia. Knee ligaments examinations did not reveal any pathological finding. Closed reduction was performed and fixed using 2 femoral lateral-medial Scanz pins and 2 tibial anteriorto-posterior Scanz pins, and the external fixator was connected with the use of rods and clamps (Fig. 2). Because the patient developed compartment syndrome, compartment release was performed through doubleincision fasciotomy and the wounds were covered by vacuum-assisted closure (Fig. 3). While exploring the popliteal artery of the right knee, popliteal artery trunk was found transected (Fig. 4) and thus end-to-end repair was done by a vascular surgery team. Slightly decreased

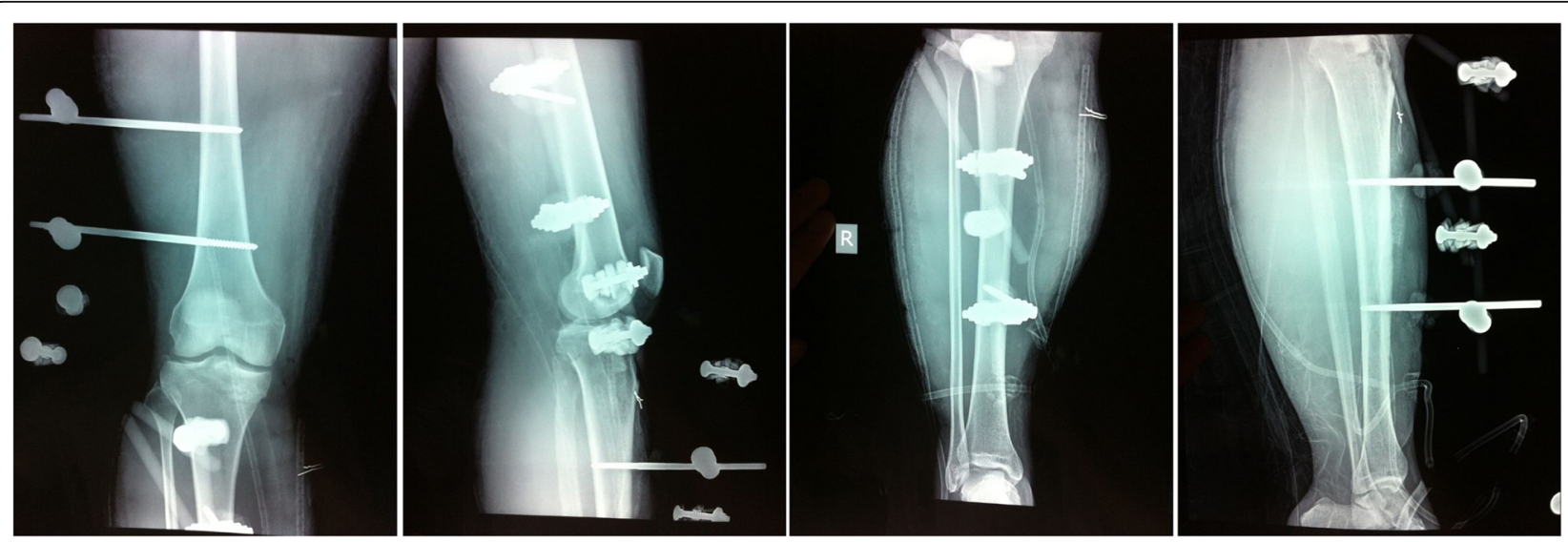

Fig. 2 Postoperative radiographs. The fracture was fixed with external fixator 


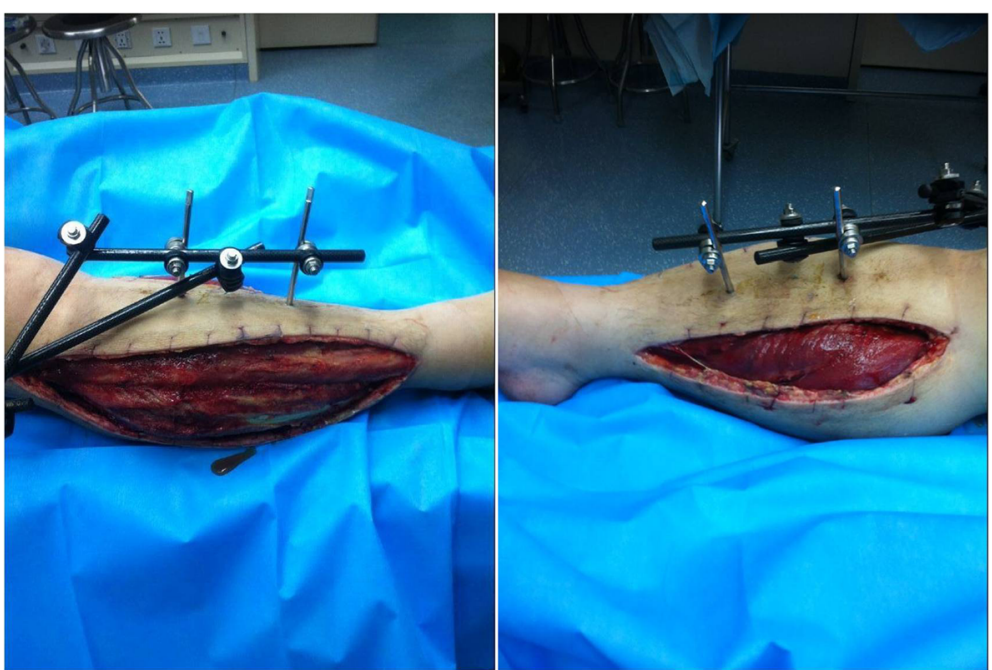

Fig. 3 Intraoperative picture of lateral(left) and medial(right) incision of compartment decompression

dorsalis pedis arterial pulses were recovered immediately postoperatively. The patient was transfused 2 units of blood for hematocrit $<26 \%$.

Twelve hours after surgery, the anticoagulant was started. Heparin intravenous infusion was given for 5 days and rivaroxaban for 3 months. Debridement was performed again 2 days after the first operation, and the devitalized peroneus longus was removed. Fasciotomy wound was closed on the 14th day after surgery. The patient refused to be treated with internal fixation and was discharged after 4 weeks of inpatient treatment with satisfactory distal limb perfusion. Follow-up was carried out in the outpatient department. The external fixator was removed and knee mobilization started at 12 weeks. Without strict rehabilitation schedule, the patient recovered very well although foot drop had not been improved. The neurological examination was checked and

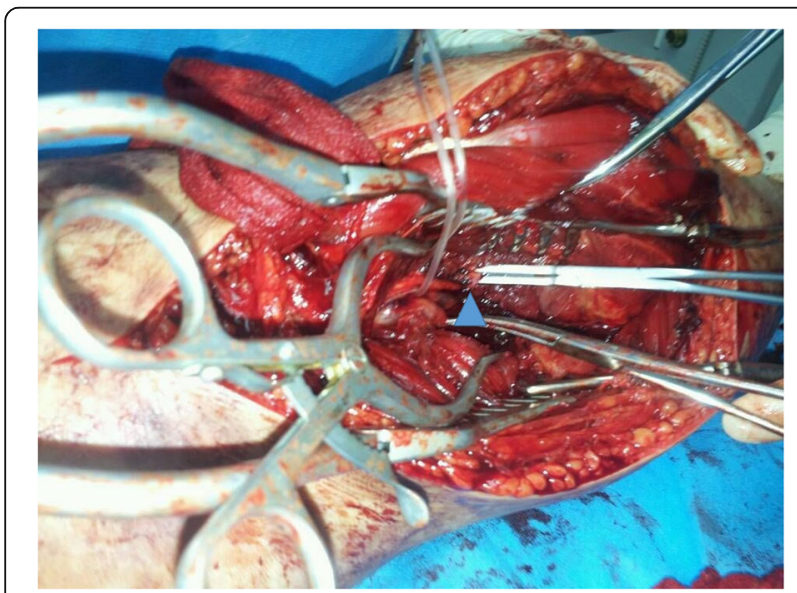

Fig. 4 Popliteal artery transection (blue triangle) was observed intraoperatively common peroneal nerve injury was excluded. During the post-operation follow-up, no complication was developed in the wound. At the 1 year follow up, the patient acquired good stability of his right knee with full range of motion. During the whole treatment process, the patient was very satisfied with the treatment and recovery.

\section{Discussion and conclusion}

Popliteal artery transection injury is a condition resulting in limb necrosis or amputation that can be potentially life-threatening [4]. Severe trauma, including open fracture, gunshot wounds, stabs, knee dislocation and complex fracture of the proximal tibia or distal femur are the principal causes of the high rates of amputation in popliteal artery trauma (Table 1) [5-15]. There have been no reports of vascular injury associated with tibial plateau fracture in the absence of displacement or dislocation in adults.

The distal portion of the popliteal artery lies close to the posterior aspect of the proximal tibia, where the firm connective tissue septa maintains the position of the vessel against the knee capsule. Therefore, the popliteal artery is fixed proximally to the popliteal fossa. Once displaced fractures or dislocations occur, the popliteal artery has no buffering room and so becomes vulnerable to injury. The mechanisms of popliteal artery transection injury caused by minimally displaced proximal tibial fracture may be due to the presence of transient fracture dislocation, the patient's autonomic response after injury possibly leading to spontaneous reduction of the fracture.

Rapid diagnosis and surgery decrease the period of ischemia and thus, the rate of amputation. A common means of diagnosis of popliteal artery injury is Doppler ultrasound, the gold standard being angiography [11] 
Table 1 The causes of popliteal artery injury

\begin{tabular}{|c|c|c|c|c|c|}
\hline \multirow[t]{2}{*}{ Authors } & \multicolumn{3}{|l|}{ Open injury } & \multicolumn{2}{|l|}{ Close injury } \\
\hline & Fracture/dislocation & Gunshot & $\overline{S t a b}$ & knee dislocation & Displaced fracture \\
\hline Leclerc et al. 2018 [5] & 20 & 3 & & & \\
\hline Wagner et al. 1994 [6] & & 99 & 7 & & \\
\hline Nicandri et al. 2010 [7] & & & & 6 & \\
\hline Miranda et al. 2002 [8] & & & & 6 & \\
\hline Papadopoulos et al. 2006 [9] & & & & & 1 \\
\hline Hesse et al. 2006 [10] & & & & & 1 \\
\hline Klineberg et al. 2004 [1 1] & & & & 12 & \\
\hline Shinomiya et al. 2018 [12] & & & & & 1 \\
\hline Bonnevialle et al. 2006 [13] & 5 & & & 5 & 1 \\
\hline Steele et al. 2012 [14] & & & & 1 & \\
\hline Treiman et al. 1992 [15] & & & & 27 & \\
\hline
\end{tabular}

However, both methods are time consuming. Time is the most important factor that determines whether a patient's limb can be saved, the literature indicating that limb ischemia of a duration greater than $6 \mathrm{~h}$ results in the proportion of necrosis or amputation in limbs likely to reach $30 \%$ [16]. For each additional hour, this rate increases by $12 \%$ [17]. Subasi et al. suggested that physical examination findings, such as bleeding from a penetrating wound, pulsatile hematoma, or the absence of a distal pulse, are sufficient to establish a diagnosis of the injury [18]. Therefore, following consultation with a vascular surgeon in cases such as these, patient are transferred directly to the operation theater 30 mins after arrival in the emergency department. This greatly saves time, contributing to eventual preservation of the affected limb.

Even if a pulse was detected, popliteal artery injury should be considered, as there may be perfusion anomalies. In such cases, measurement of the ankle-brachial index (ABI) is the subsequent consideration in suspected cases. Patients with an ABI $\geq 0.9$ may be observed. For an ABI below 0.9, CT, angio or Doppler are required, followed by immediate vascular exploration and repair if positive findings so mandate [19]. We did not utilize these methods as the case was clinically apparent by the absence of a pulse.

There are a number of commonly recognized fracture patterns that involve either the medial or lateral tibial condyle. Tibial plateau fractures that involve the medial plateau, as in the present case, exhibit an increased risk of development of compartment syndrome and neurovascular injury compared with the lateral counterpart [20].

Any delay in treatment of acute compartment syndrome can be catastrophic, leading to serious complications such as permanent sensory and motor deficit, contractures, infection, and at times, amputation of the limb [21-23]. If there is clinical presentation such as pain with passive stretch of the muscles, paresthesia, paralysis and lack of a pulse, the fascia compartment should be decompressed thoroughly as soon as possible. If the clinical presentation is not so apparent, and duration of limb ischemia is greater than $5 \mathrm{~h}$, preventive fasciotomy should be performed to avoid reperfusion injury.

Given below are a few recommendations regarding this case. Firstly, surgeons should pay attention to the possibility of vascular damage in knee joint injury, even if there is no fracture or dislocation, or the fracture is minimally displaced. Secondly, auxiliary examination should not be relied upon, and the observation that saved time saves limbs should be remembered. Thirdly, for suspicious injuries whose symptoms are not apparent, clinical examination using the $\mathrm{ABI}$ is valuable as an alternative. Fourthly, fascia compartment decompression should be performed using quick thinking and decisive action.

In conclusion, we have reported a rare case of popliteal artery transection injury with minimally displaced tibial plateau fracture. As popliteal artery transection injury is potentially catastrophic, the possibility of vascular injury should be considered in knee joint injury, even if there is no fracture or dislocation, or when the fracture is minimally displaced. If this occurs, the patient should be treated immediately and thoroughly.

\section{Abbreviation}

ABI: Ankle-brachial index

\section{Acknowledgements}

Not applicable.

Authors' contributions

LT designed the study, YWL and YHL drafted the manuscript, YL carried out radiological evaluation, $T Y^{2}$ made the diagnosis and performed the surgery, YWL participated in literature search. YWL, YHL and $T Y^{1}$ contributed equally to this study. TY ${ }^{1}$ corresponding to Tiecheng Yu. All authors read and approved the final manuscript. 


\section{Funding}

Not applicable.

\section{Availability of data and materials}

The dataset supporting the conclusions of this article is included within the article.

\section{Ethics approval and consent to participate}

This study was carried out in accordance with the guidelines for the care for human study adopted by the First Hospital of Jilin University, the protocol was approved by the Research Ethics Committee of the First Hospital of Jilin University (Ref. no: 2013/061), and written informed consent was obtained from all participants.

\section{Consent for publication}

Written informed consent was obtained from the patient for the publication of this case report and any accompanying images. A copy of the written consent is available for review by the Editor-in-Chief of this journal.

\section{Competing interests}

The authors declare that they have no competing interests.

\section{Author details}

'Department of Orthopedic Trauma, The First Hospital of Jilin University, Changchun, No. 71 Xinmin Street, Changchun, Jilin, China. ${ }^{2}$ Department of Cardiology and Echocardiography, the First Hospital of Jilin University, Changchun 130021, China. ${ }^{3}$ Department of Plastic and Cosmetic Surgery, the First Hospital of Jilin University, Changchun 130021, China. ${ }^{4}$ Department of Hematology, the First Hospital of Jilin University, Changchun 130021, China.

Received: 27 November 2019 Accepted: 22 January 2020

Published online: 30 January 2020

\section{References}

1. Frykberg ER. Popliteal vascular injuries. Surg Clin North Am. 2002;82(1):67-89.

2. Hafez HM, Woolgar J, Robbs JV. Lower extremity arterial injury: results of 550 cases and review of risk factors associated with limb loss. J Vasc Surg. 2001:33(6):1212-9

3. Tjoumakaris FP, Wells L. Popliteal artery transection complicating a nondisplaced proximal tibial epiphysis fracture. Orthopedics. 2007;30(10):876-7.

4. Reid JJ, Kremen TJ Jr, Oppenheim WL. Death after closed adolescent knee injury and popliteal artery occlusion: a case report and clinical review. Sports health. 2013;5(6):558-61.

5. Leclerc B, Boyer E, Menu G, Leclerc G, Sergent P, Ducroux E, Salomon Du Mont L, Garbuio P, Rinckenbach S, Obert L. Two-team management of vascular injuries concomitant with osteo-articular injuries in 36 patients over six years. Orthop Traumatol Surg Res. 2018:104(4):497-502.

6. Wagner WH, Yellin AE, Weaver FA, Stain SC, Siegel AE. Acute treatment of penetrating popliteal artery trauma: the importance of soft tissue injury. Ann Vasc Surg. 1994;8(6):557-65.

7. Nicandri GT, Dunbar RP, Wahl CJ. Are evidence-based protocols which identify vascular injury associated with knee dislocation underutilized? Knee Surg Sports Traumatol Arthrosc. 2010;18(8):1005-12.

8. Miranda FE, Dennis JW, Veldenz HC, Dovgan PS, Frykberg ER. Confirmation of the safety and accuracy of physical examination in the evaluation of knee dislocation for injury of the popliteal artery: a prospective study. J Trauma. 2002;52(2):247-51 discussion 251-242.

9. Papadopoulos AX, Panagopoulos A, Kouzelis A, Gliatis I, Dimakopoulos P. Delayed diagnosis of a popliteal artery rupture after a posteromedial tibial plateau fracture-dislocation. J Knee Surg. 2006;19(2):125-7.

10. Hesse E, Bastian L, Zeichen J, Pertschy S, Bosch U, Krettek C. Femoral avulsion fracture of the posterior cruciate ligament in association with a rupture of the popliteal artery in a 9-year-old boy: a case report. Knee Surg Sports Traumat Arthrosc. 2006;14(4):335-9.

11. Klineberg EO, Crites BM, Flinn WR, Archibald JD. The role of arteriography in assessing popliteal artery injury in knee dislocations. J Trauma. 2004;56(4): 786-90

12. Shinomiya R, Sunagawa T, Nakashima Y, Nakabayashi A, Makitsubo M, Adachi N. Slow progressive popliteal artery insufficiency after neglected proximal tibia physeal fracture: a case report. J Pediatr Orthop B. 2018;27(1):35-9.
13. Bonnevialle $P$, Chaufour $X$, Loustau $O$, Mansat P, Pidhorz L, Mansat M. Traumatic knee dislocation with popliteal vascular disruption: retrospective study of 14 cases. Rev Chir Orthop Reparatrice Appar Mot. 2006;92(8):768-77.

14. Steele $\mathrm{HL}$, Singh A. Vascular injury after occult knee dislocation presenting as compartment syndrome. J Emerg Med. 2012;42(3):271-4.

15. Treiman GS. Examination of the patient with a knee dislocation. Arch Surg. 1992;127(9):1056.

16. Kim JW, Sung CM, Cho SH, Hwang SC. Vascular injury associated with blunt trauma without dislocation of the knee. Yonsei Med J. 2010:51(5):790-2

17. $X u$ YQ, Li Q, Shen TG, Su PH, Zhu YZ. Early diagnosis and treatment of trauma in knee joints accompanied with popliteal vascular injury. Int J Clin Exp Med. 2015;8(6):9421-9.

18. Subasi M, Cakir O, Kesemenli C, Arslan H, Necmioglu S, Eren N. Popliteal artery injuries associated with fractures and dislocations about the knee. Acta Orthop Belg. 2001:67(3):259-66.

19. Boyce RH, Singh K, Obremskey WT. Acute Management of Traumatic Knee Dislocations for the generalist. J Am Acad Orthop Surg. 2015;23(12):761-8.

20. Wahlquist $M$, laguilli $N$, Ebraheim $N$, Levine J. Medial tibial plateau fractures: a new classification system. J Trauma. 2007;63(6):1418-21.

21. Prasarn ML, Ouellette EA, Livingstone A, Giuffrida AY. Acute pediatric upper extremity compartment syndrome in the absence of fracture. J Pediatr Orthop. 2009:29(3):263-8.

22. Mullett $\mathrm{H}$, Al-Abed K, Prasad CV, O'Sullivan M. Outcome of compartment syndrome following intramedullary nailing of tibial diaphyseal fractures. Injury. 2001;32(5):411-3.

23. Shadgan B, Menon M, Sanders D, Berry G, Martin C Jr, Duffy P, Stephen D, O'Brien PJ. Current thinking about acute compartment syndrome of the lower extremity. Can J Surg J Can Chir. 2010;53(5):329-34.

\section{Publisher's Note}

Springer Nature remains neutral with regard to jurisdictional claims in published maps and institutional affiliations.

Ready to submit your research? Choose BMC and benefit from:

- fast, convenient online submission

- thorough peer review by experienced researchers in your field

- rapid publication on acceptance

- support for research data, including large and complex data types

- gold Open Access which fosters wider collaboration and increased citations

- maximum visibility for your research: over $100 \mathrm{M}$ website views per year

At BMC, research is always in progress.

Learn more biomedcentral.com/submissions 